\title{
Desain Tampilan Aplikasi Sistem Pelayanan Masyarakat Desa Dengan Metode Goal-Directed Design
}

\author{
Anita Muliawati $^{1}$, Tri Rahayu ${ }^{2}$, Intan Hesti Indriana ${ }^{3}$, Kraugusteeliana ${ }^{4}$ \\ Dosen Universitas Pembangunan Nasional Veteran Jakarta ${ }^{1,2,3,4}$ \\ Jalan RS. Fatmawati Pondok Labu Jakarta \\ Sur-el : anitamuliawati@ upnvj.ac.id ${ }^{1}$, trirahayu@ upnvj.ac.id ${ }^{2 *}$, hesti@upnvj.ac.id ${ }^{3}$, \\ gusteeliana@gmail.com ${ }^{4}$
}

\begin{abstract}
The village is the initial milestone of the success of the government, all government data comes from the village which will later be processed further. Thus, an application is needed so that the data can be processed easily. There are many obstacles experienced by the village, especially the village of Sukamanah in Serang Banten. Where service is part of the problem that often occurs because it is still using manual services. The computer in Sukaman Village, Serang, Banten, is only used as a data storage process, but for service activities, residents still have to come and sometimes in taking care of family cards, residents may have to come to the village several times. So it is hoped that the village service application will make the service process to the villagers faster. This study aims to design a user interface based on the needs of the Sukamanah village on the village information system using the Goal-Directed Design method which consists of 6 phases. Research phase, looking for system requirements desired by users. The modeling phase is looking for user characteristics by creating a user persona. Requirements phase, generate user scenarios and explain system requirements using Hierarchical Task Analysis. The framework definition phase, creating an interface structure in the form of wireframing. Refinement phase, perfecting the interface structure to a high-fidelity form. The development support phase is a qualitative testing phase for users by using an assessment based on the System Usability Scale (SUS) to get feedback on the village information system prototype that fits the needs
\end{abstract}

Keywords: Application, Village Service, User Interface, Goal-Directed Design, System Usability Scale

\begin{abstract}
Abstrak : Desa merupakan tonggak awal dari suksesnya pemerintahan, semua data-data pemerintahan berawal berasal dari desa yang nanti data tersebut diproses lebih lanjut. Dengan demikian dibutuhkan suatu aplikasi agar data tersebut dapat diproses dengan mudah. Banyaknya kendala yang dialami oleh desa, khususnya desa sukamanah diSerang banten. Dimana pelayanan merupakan bagian dari permasalah yang sering terjadi dikarenakan masih menggunakan pelayanan yang bersifat manual. Komputer yang pada desa sukaman Serang banten Hanya sebagai proses penyimpanan data, namun kegiatan pelayanannya warga masih harus datang dan kadang dalam mengurus kartu keluarga warga bisa beberapa Kali harus datang ke desa tersebut. Sehingga diharapkan dengan adanya aplikasi pelayanan desa membuat proses pelayannya kepada warga desa menjadi lebih cepat. Penelitian ini bertujuan untuk merancang aplikasi pelayanan masyarakat desa berdasarkan kebutuhan pihak desa Sukamanah pada sistem informasi desa dengan menggunakan metode Goal-Directed Design yang terdiri dari 6 fase. Fase research, mencari kebutuhan sistem yang diinginkan oleh pengguna. Fase modelling,mencari karakteristik pengguna dengan membuat user persona. Fase requirement, menghasilkan skenario pengguna dan menjelaskan kebutuhan sistem dengan menggunakan Hierarchical Task Analysis. Fase framework definition, membuat struktur antar muka dalam bentuk wireframing. Fase refinement, menyempurnakan struktur antar muka ke bentuk high-fidelity. Fase development support, merupakan fase pengujian kualitatif kepada pengguna dengan menggunakan penilaian berdasarkan System Usability Scale (SUS) untuk mendapatkan umpan balik terhadap prototype sistem informasi desa yang sesuai dengan kebutuhan.
\end{abstract}

Kata kunci: Aplikasi, Pelayanan Desa, User Interface, Goal-Directed Design, System Usability Scale 


\section{PENDAHULUAN}

Perkembangan Teknologi informasi di era saat ini sangat berkembang pesat, dan di seluruh belahan dunia penggunaan teknologi informasi telah dilakukan termasuk di Indonesia. Dimana teknologi informasi, dapat membantu proses seluruh pekerjaan yang ada dengan lebih efektif dan efisien. Termasuk pada pengelolaan birokrasi, administrasi publik dan pelayanan publik yang ada pada lembaga yang dimulai dari tingkat pusat hingga desa.

Dimana desa merupakan data awal yang akan diolah didalam pemerintahan, sehingga perlunya adanya sistem aplikasi yang mempermudah dari segi pelayanan desa. Dengan adanya aplikasi tersebut diharapkan data yang diperoleh dapat dengan mudah dan cepat dengan demikian pemerintah bisa dengan cepat pula mengetahuin kondisi dari tiap-tiap desa sehingga tindak atau keputusan apa yang akan dilakukan dapat dilakukan dengan cepat dan tepat.

Salah satu contohnya adalah Desa Sukamanah di Kecamatan Baros, Kabupaten Serang, Provinsi Banten. Desa tersebut merupakan desa dengan indeks desa mandiri berkategori maju yang wilayahnya terdiri dari 5 Rukun Warga, dan 21 Rukun Tetangga dengan penduduk sebanyak 6448 jiwa. Desa ini mendapat bantuan berupa dana desa yang diberikan oleh Kementerian Desa, Pembangunan Daerah Tertinggal, dan Transmigrasi Republik Indonesia. Dana yang dimiliki tersebut digunakan untuk mengelola segala kebutuhan desa yang dapat membantu memajukan desa tersebut.
Dalam mengelola desa, Desa Sukamanah tidak memiliki sistem informasi. Pihak Desa Sukamanah hanya menggunakan sistem informasi keuangan yang berasal dari Pemerintah Kabupaten Serang. Sedangkan dalam pelayanan kepada warga desa sudah menggunakan sistem terkomputerisasi berupa penggunaan aplikasi Microsoft Word dan Microsoft Excel. Aplikasi Microsoft Word digunakan aparatur desa dalam membuat suratsurat seperti surat perizinan, surat kematian, dll. Sedangkan aplikasi Microsoft Excel digunakan untuk membuat data kependudukan warga desa. Pihak Desa Sukamanah sudah diberikan sistem informasi, akan tetapi sistem tersebut tidak mudah untuk dipahami kemudian ditambah dengan minimnya akses internet sehingga menyebabkan kesulitan dalam menggunakan sebuah sistem informasi. Demi dapat memberikan pelayanan publik yang cepat dan efisien, maka pihak Desa Sukamanah mengharapkan desain user interface pada rancangan sistem informasi desa berbasis website yang mudah dipahami dan dapat mempercepat pelayanan kepada warga desa.

Berdasarkan permasalahan tersebut, dalam proses membuat desain aplikasi pelayanan masyarakat desa yang sesuai keinginan warga desa dan pihak desa, maka metode GoalDirected Design (GDD) akan penulis gunakan dalam melakukan penelitian ini. Metode tersebut memiliki beberapa fase diantaranya research, modelling, requirement, framework definition, refinement, dan development support [1]. Metode GDD sangat cocok untuk digunakan karena metode ini memiliki orientasi fokus 
terhadap keinginan dan tujuan pengguna yang dimana hasil dari desain tersebut dapat memudahkan warga desa ketika membutuhkan pelayanan dan memudahkan pihak desa di dalam memberikan pelayanan kepada warga desa. Setelah proses observasi dan wawancara dilakukan, peneliti dapat mengetahui keinginan warga desa terhadap rancangan desain sistem informasi desa sehingga dengan adanya metode GDD ini dapat dijadikan sebagai dasar pedoman dalam merancang sebuah user interface sistem informasi desa. Kemudian melakukan proses pengujian terhadap rancangan user interface yang telah dibuat dengan menggunakan System Usability Scale (SUS) yang dilakukan untuk mendapatkan umpan balik dari pengguna[2].

\section{METODOLOGI PENELITIAN}

Metode dalam melakukan penelitian ini menggunakan Goal-Directed Design (GDD). Berikut ini merupakan langkah-langkah penelitian yang harus dilakukan sesuai dengan metode GoalDirected Design (GDD).

\subsection{Studi Literatur}

Pada penelitian ini penulis melakukan studi literatur yang merupakan bagian dari pengumpulan data dengan melihat jurnal dan buku untuk mengetahui implementasi metode Goal Directed Design (GDD) pada pembuatan user interface. Kemudian standar System Usability Scale (SUS) yang dijadikan sebagai acuan dalam mengukur tingkat kesesusaian kebutuhan dan kepuasan pengguna.

\subsection{Research}

Tahapan research merupakan tahapan dalam mencari kebutuhan pendukung yang dibutuhkan untuk melengkapi hasil dari studi literatur yang terdiri 3 langkah kerja, diantaranya:

1. Menentukan Scope

Menentukan batasan atau scope merupakan hal yang penting karena tujuan dari menentukan batasan adalah memudahkan peneliti dalam meneliti objek penelitiannya. Batasan yang penulis gunakan yaitu mengambil populasi berdasarkan pada tujuan penelitian agar dapat menjawab permasalahan yang ada pada penelitian ini dengan menentukan para stakeholder yaitu aparatur desa.

\section{Melakukan Observasi}

Melakukan observasi atau pengamatan langsung terhadap objek yaitu desa Sukamanah. Observasi dilakukan untuk memastikan bahwa scope atau batasan yang ditentukan sudah sesuai dan dapat diteruskan ke fase selanjutnya.

3. Wawancara

Wawancara bertujuan untuk mencari tahu permasalahan yang dihadapi saat ini dan memastikan bahwa masalah yang ada tersebut benar dan asli sehingga penulis dapat memberikan hasil analisa dan solusi dari permasalahan terhadap penelitian yang dilakukan. 


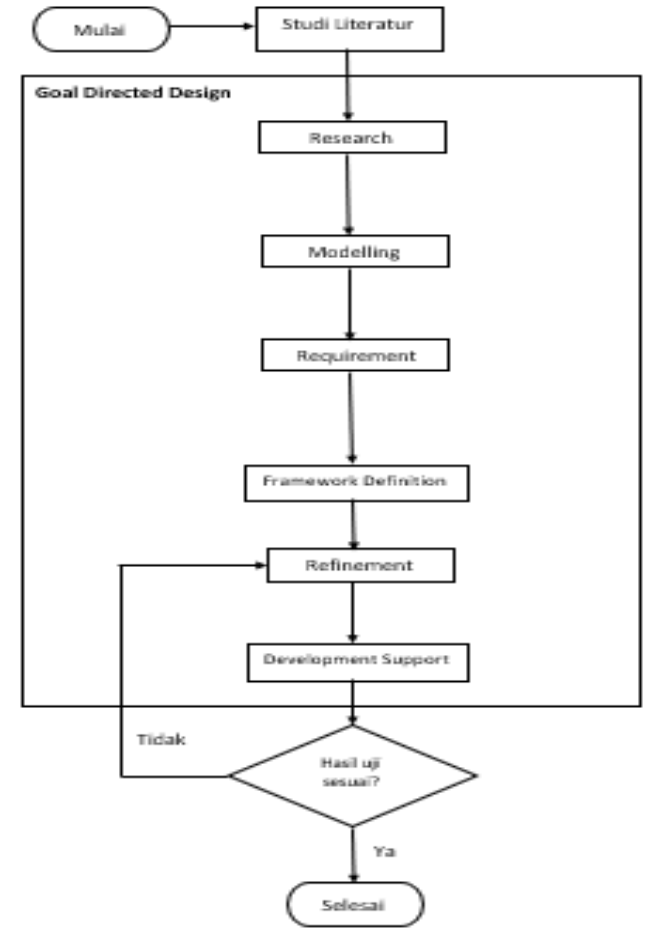

\section{Gambar 1. Alur Penelitian}

\subsection{Modelling}

Hasil research yang telah dikumpulkan kemudian dilakukan proses modelling yaitu memodelkan hasil research ke dalam bentuk model persona atau user persona yang memuat informasi pendukung penelitian.

Persona yang sudah dikumpulkan kemudian didefinisikan ke dalam beberapa variable diantaranya; Usia,, Pekerjaan, Perangkat yang digunakan, Aktivitas, Permasalahan yang dihadapi, Tujuan atau motivasi dan Kebutuhan [3].

\subsection{Requirement}

Fase requirement adalah fase penyesuaian antara user persona dengan tujuan dan kebutuhan spesifik pengguna sehingga membuat keseimbangan kebutuhan dan tujuan dengan desain user interface yang diharapkan. Dalam merancang user persona menjadi kebutuhan terdapat dua tahap yaitu:[4]

1) Menentukan Desain Struktur Informasi

Tahap ini dilakukan untuk menentukan konten yang sesuai dengan keinginan dari perangkat desa yang telah dijelaskan pada tahap modelling, kemudian didefinisikan menjadi desain struktur informasi atau struktur menu.

2) Membuat Konteks Skenario

Konteks skenario merupakan hasil dari permintaan atau requirement dari perangkat desa menjadi sebuah rancangan interaksi awal tanpa harus memahami lebih dalam sistem operasi yang akan digunakan berdasarkan pada hasil desain struktur informasi yang telah didefinisikan.

\subsection{Framework Definition}

Fase framework definition merupakan pengolahan hasil dari research, modelling, dan requirement yang kemudian didefinisikan menjadi sketsa rancangan user interface yang mempunyai tahapan dan memiliki interaksi. Hasil dari fase ini adalah wireframe yang memiliki layout, informasi yang digunakan, dan langkah-langkah kerja yang dapat memberikan interaksi awal.

\subsection{Refinement}

Setelah wireframe dibuat kemudian pada fase refinement dilakukan penyempurnaan user interface menjadi mockup yang memiliki tingkat kemiripan tertinggi dengan sistem yang dirancang atau high-fidelity [5]. Penyempurnaan terhadap user interface yang dilakukan seperti 
memberikan pewarnaan dan penambahan informasi sehingga sistem tersebut dapat memberikan interaksi yang lebih detail dan sesuai dengan sistem yang dibuat atau disebut sebagai prototype, kemudian prototype yang sudah jadi dievaluasi oleh stakeholder pada fase selanjutnya.

\subsection{Development Support}

Fase ini merupakan tahap pengembangan user interface yang dirancang dengan melakukan evaluasi terhadap user interface tersebut. Dalam proses mendukung pengembangan dilakukan beberapa langkah [6]:

1. Pengujian prototype

Proses pengujian prototype dilakukan untuk mengetahui interaksi antar layout yang ada dan prototype tidak memiliki masalah sebelum di uji kepada stakeholder.

2. Evaluasi prototype menggunakan SUS

Kemudian proses evaluasi prototype diujikan kepada stakeholder dengan menggunakan System Usability Scale (SUS) yang disajikan dalam bentuk kuesioner dengan 10 pertanyaan dan diisi oleh stakeholder yang menguji prototype tersebut dengan menggunakan skala likert dan instrumen ratingscale. Adapun 5 skala yang digunakan antara lain:

a. Bermakna sangat tidak setuju/sangat tidak baik.

b. Bermakna tidak setuju/tidak baik.

c. Bermakna netral/netral.

d. Bermakna setuju/baik.

e. Bermakna sangat setuju/sangat baik.
Untuk menilai hasil pengujian pada System Usability Scale (SUS) memiliki beberapa aturan yaitu:

a. Setiap penilaian pada nomor ganjil akan dikurangi 1.

b. Setiap penilaian pada nomor genap maka 5 dikurangi dengan angka penilaian.

c. Hasil dari nomor ganjil dan nomor genap dijumlah dan dikalikan 2.5.

d. Nilai akhir yang keluar pada tiap responden dijumlahkan kemudian dibagi jumlah responden untuk mendapatkan nilai ratarata.

3. Analisa hasil pengujian

Analisa hasil pengujian menggunakan SUS diawali dengan mentabulasikan data yang diperoleh ke dalam Microsoft Excel. Penilaian dilihat berdasarkan pada nilai akhir setiap responden yang kemudian dirata-rata kan, kemudian hasil uji berupa nilai akhir diketahui dan digolongkan berdasarkan indikator yang dimiliki SUS dengan standar pencapaian minimum pada penelitian ini sebesar 60 maka penelitian ini dapat dikatakan selesai, kemudian hasil pengujian dan output berupa desain dapat diberikan kepada pihak Desa Sukamanah. Apabila nilai minimum 60 tidak tercapai maka penilitian tetap akan ditutup dan selanjutnya peneliti menyerahkan kepada peneliti-peneliti lain untuk memperbaiki dan mengembangkan hasil penelitian ini.

\section{HASIL DAN PEMBAHASAN}


Tahapan - tahapan yang akan dilakukan dalam membjat tampilan aplikasi system pelayanan masyarakat Desa dengan menggunakan metode Goal-Directed Design.

\subsection{Research}

Tahap ini memuat hasil wawancara dan observasi yang telah dilakukan oleh penulis terhadap pihak desa dan warga desa dengan ujuannya adalah untuk mengetahui kebutuhankebutuhan pada sistem informasi desa.

\subsection{Modelling}

Pada tahap ini adalah mengerjakan user persona yang digunakan untuk mengelompokkan calon pengguna berdasarkan hasil wawancara yang dilakukan sebelumnya terhadap 4 orang perangkat desa dari 8 orang perangkat desa yang kemudian diambil 3 orang sample yang menjabat sebagai Kaur umum, Kasi perencanaan dan pelaporan, dan Kasi Pemerintahan. Berikut merupakan hasil user persona yang sudah diperoleh.

\subsection{Requirement}

Untuk mengetahui kebutuhan yang spesifik pada sistem kemudian disesuaikan dengan user persona yang sudah dihimpun maka dibuat desain struktur informasi dan konteks skenario. Desain struktur informasi merupakan rancangan konten atau menu yang didefinisikan berdasarkan kebutuhan pada tahap modelling. Sedangkan konteks skenario bisa disebut sebagai reka adegan user ketika menggunakan sebuah sistem.

\section{Desain Struktur Informasi}

Desain struktur informasi atau struktur menu yang telah ditentukan berdasarkan hasil modelling dan memiliki tiga tingkatan user diantaranya super admin atau pengawas, administrasi-pelaporan, dan pelayanan.

\section{Konteks Skenario}

Rancangan tampilan yang dibuat harus berdasarkan konteks skenario yang dibuat sehingga dapat memberikan kemudaha ketika membuat sebuah tampilan. Konteks skenario di bawah ini disusun berdasarkan pada beberapa aktifitas antara user dengan sistem informasi desa. Terdiri dari login, Lihat Halaman Kependudukan, Tambah Data Kependudukan, Ubah Data Kependudukan, Hapus Data Kependudukan, Cetak Data Kependudukan, Akses Halaman Pengaturan Surat, Tambah Pengaturan Surat, Ubah Pengaturan Surat, Hapus Pengaturan Surat, Akses Halaman Cetak Surat, Cetak Surat, Akses Halaman Arsip Surat, Tambah Arsip Surat, Lihat Arsip Surat, Print Data Arsip Surat, Akses Halaman Statistik, Penentuan Kategori dan Bentuk Data Statistik, Akses Halaman Kas Desa, Tambah Data Kas Desa, Print Data Kas Desa, Akses Halaman Inventaris, Tambah Data Inventaris, Ubah Data Inventaris, Print Data Inventaris, Akses Halaman Administrator, Tambah Administrator, Ubah Password Administrator dan Hapus Administrator.

Gambar 2 menunjukkan skenario login yang dapat dilakukan oleh admin dengan peran superadmin, administrasi-pelaporan, dan pelayanan pada sistem informasi desa. 


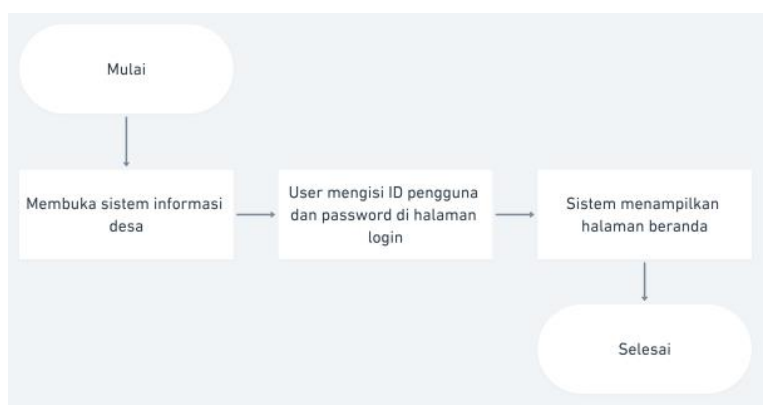

Gambar 2. Skenario Login

Pada sistem ini, perangkat desa yang ingin menggunakan sistem informasi desa ini harus mempunyai id pengguna dan kata sandi yang diberikan oleh superadmin selaku pengelola dan penanggung jawab sistem informasi desa.

\subsection{Framework Definition}

Tahap ini merupakan tahapan pembuatan wireframe yang memiliki layout, informasi yang digunakan, langkah-langkah kerja yang dapat memberikan interaksi awal. Tahap ini merupakan proses pendefinisian dari requirement yang dibutuhkan menjadi sebuah tampilan mediumfidelity berupa wireframe dan kebutuhan lain seperti jenis typography dan pewarnaan yang akan digunakan untuk membuat tampilan high-fidelity berupa mock up [7].

Pada rancangan desain website sistem informasi desa ini menggunakan font jenis montserrat dengan beberapa ukuran seperti 36 dan 24 untuk setiap judul yang ada di setiap halaman, sedangkan untuk isi konten menggunakan ukuran 14 dan 18.

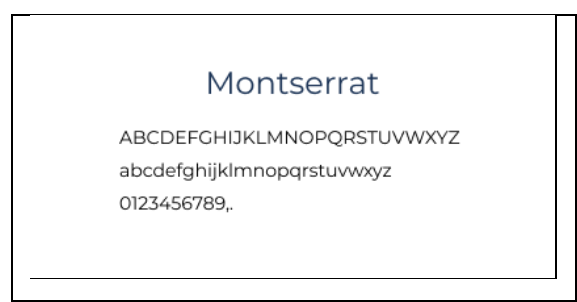

Gambar 3. Font tampilan aplikai pelayanan masyarakat desa
Warna yang digunakan untuk rancangan sistem informasi desa menggunakan warnawarna yang cerah dan mudah terlihat agar pihak desa Sukamanah tidak merasa kesulitan ketika menggunakan sistem informasi desa.

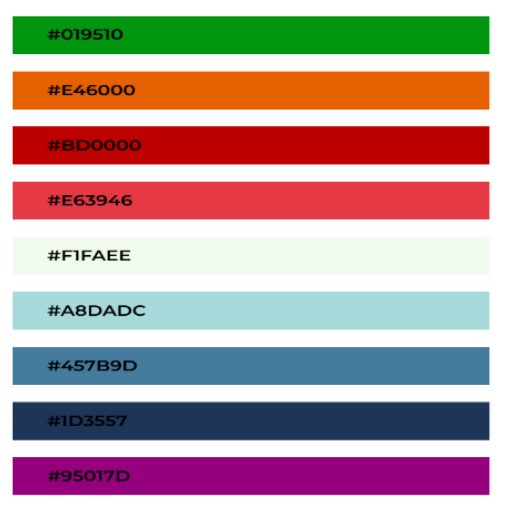

Gambar 4. Colour Pallete tampilan aplikasi pelayanan masyarakat desa

\subsection{Refinement}

Tahapan ini adalah lanjutan dari tahap framework definition dengan melakukan pembangunan detil desain pada setiap komponen user interface untuk menghasilkan tampilan berbentuk mockup [8].

Berikut ini ada beberapa tampilan mockup aplikasi pelayanan masyarakat Desa;

1. Halaman Login

Berfungsi sebagai pintu masuk untuk perangkat desa melakukan kegiatan pada sistem informasi desa dengan memasukkan id admin dan kata sandi

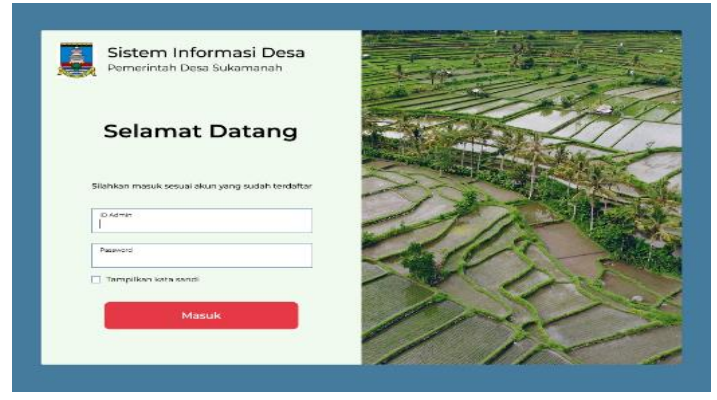

Gambar 5. Mockup Login 
Ketika perangkat desa memasukkan id admin, password dan menekan tombol masuk maka akan langsung diarahkan menuju halaman beranda, selain itu perangkat desa juga dapat menampilkan password apalagi merasa ragu password yang dimasukkan sudah benar atau belum benar. Untuk dapat masuk ke dalam sistem informasi desa, perangkat desa harus meminta id dan password kepada admin.

2. Halaman Beranda

Halaman beranda merupakan halaman utama pada sistem informasi desa yang memiliki konten berupa shortcut untuk navigasi ke beberapa halaman dan juga terdapat menu sebagai navigator utama pada website sistem informasi desa seperti yang terlihat pada tampilan mockup di gambar 6.

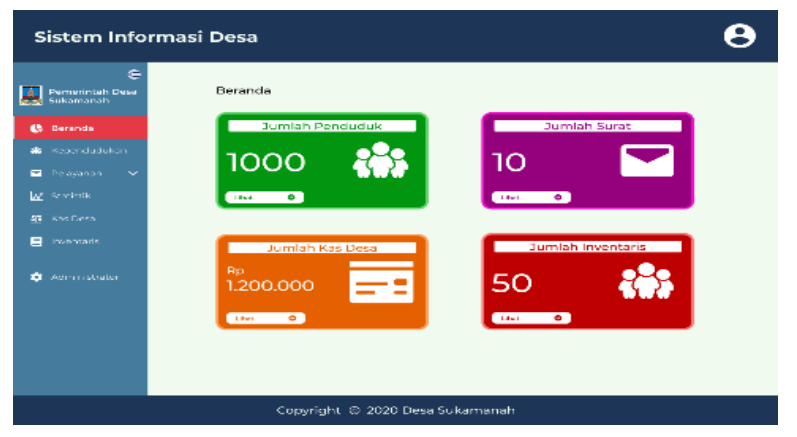

Gambar 6. Mockup Beranda

Menu yang tersedia pada rancangan sistem informasi desa adalah untuk memberikan tombol perpindahan antar halaman seperti menu beranda, kependudukan, pelayanan, statistik, kas desa, inventaris, dan administrator. Selain itu konten utama pada halaman beranda ini terdapat beberapa statistik seperti jumlah penduduk, jumlah surat, jumlah kas desa, dan jumlah inventaris yang masing-masing memiliki tombol untuk langsung menuju ke halaman kependudukan, pengaturan surat, kas desa, dan inventaris.

3. Halaman Pelayanan
Pada menu pelayanan memiliki beberapa sub-menu. Pada dasarnya fungsi pelayanan yang ada di sistem informasi adalah untuk pelayanan surat sesuai dengan keinginan dari perangkat desa. Terdapat beberapa sub halaman dari halaman pelayanan seperti halaman pengaturan surat, halaman tambah pengaturan surat, halaman ubah pengaturan surat, halaman simpan pengaturan surat, halaman cetak surat, halaman form cetak surat, halaman arsip surat, halaman form arsip surat, halaman lihat arsip surat, dan halaman sukses simpan surat.

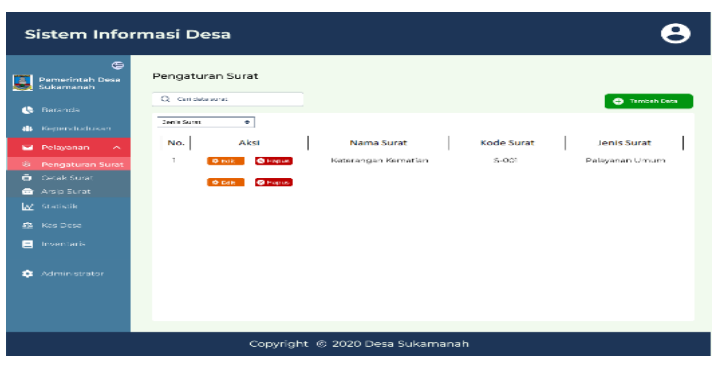

\section{Gambar 7 Mockup Pengaturan Surat}

Halaman pengaturan surat berfungsi untuk melihat daftar pengaturan surat yang sudah dimasukkan ke dalam sistem, kemudian tersedia tombol tambah yang memiliki fungsi untuk menambahkan pengaturan surat, untuk melihat surat dan menghapus surat terdapat tombol lihat surat dan hapus surat pada kolom aksi yang terdapat di bagian konten daftar surat.

\section{Arsip Surat}

Merupakan tampilan untuk menyimpan surat masuk dan surat keluar agar perangkat desa tidak khawatir apabila surat fisik hilang atau rusak. Terdapat kotak pencarian surat untuk mencari surat berdasarkan nama surat, tanggal surat, maupun jenis surat. Untuk menambah surat yang ingin diarsip tersedia tombol tambah data, dan untuk mencetak arsip data surat tersedia tombol print. 


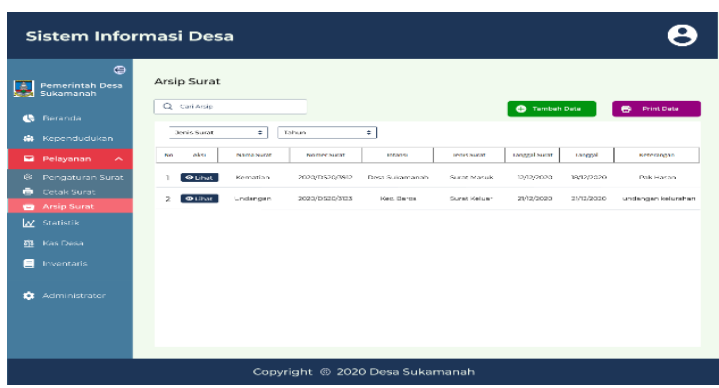

Gambar 8 Mockup Arsip Surat

\subsection{Development Support}

Tahap development support merupakan tahapan evaluasi terhadap rancangan tampilan pada sistem informasi yang telah dibuat. Tahapan evaluasi yang dimaksud adalah evaluasi terhadap interaksi yang dimiliki oleh user interface, evaluasi kesesuaian user interface dengan kebutuhan stakeholders, dan evaluasi user experience atau pengalaman pengguna untuk mencapai kepuasan terhadap tampilan user interface. Pada tahap ini dilakukan dengan menggunakan kuesioner dengan standar System Usability Scale (SUS) [9].

\section{Menyiapkan Kuesioner}

Kuesioner yang diberikan kepada sampel terdiri dari 10 pertanyaan dasar yang digunakan pada metode System Usability Scale (SUS) dengan menggunakan 5 skala likert mulai dari "Sangat Tidak Setuju" hingga "Sangat Setuju".

\section{Uji Coba Prototype dan Evaluasi}

Proses uji coba pada protoype dengan menyebarkan kuesioner kepada 8 orang perangkat desa dan kemudian dilakukan tabulasi data berdasarkan data kuesioner yang sudah diisi oleh perangkat desa. Responden diminta untuk membuka dan menelusuri rancangan user interface sistem informasi desa yang sudah dibuat menggunakan metode Goal Directed Design
(GDD) dan setelah itu mengisi kuesioner yang diberikan kepada responden.

Dari hasil tabulasi data berdasarkan data kuesioner yang telah diisi oleh responden dengan menggunakan metode System Usability Scale (SUS) memberikan nilai total rata-rata sebesar 72.5 dengan nilai akhir terkecil yaitu pada responden ke-2 sebesar 57.5, sedangkan untuk nilai akhir terbesar diberikan oleh responden ke4 dengan nilai 85 .

3. Analisa Hasil Pengujian

Hasil evaluasi akhir dari pengujian terhadap user experience pada rancangan user interface sistem informasi desa menggunakan metode System Usability Scale (SUS) menyatakan bahwa penelitian ini dianggap selesai karena hasil evaluasi akhir mendapatkan nilai rata-rata di atas 60 sedangkan yang telah dicapai yaitu 72.5 dengan Acceptabiliy Ranges mendapatkan predikat "Acceptable", tingkat Grade Scales berada pada kategori "C" , Adjective Ratings mendapatkan kategori "Good", dan Percentile Ranks mendapatkan tingkat kategori "C". Adapun penyebab dari nilai yang didapat tidak mencapai nilai maksimal karena berdasarkan pada 2 pertanyaan yang mendapat nilai rendah yaitu pertanyaan ke-4 dan pertanyaan ke-10 membuktikan bahwa untuk dapat menggunakan sistem informasi desa yang sesuai dengan rancangan user interface yang telah dibuat, perangkat desa tetap memerlukan pelatihan dan pendampingan pada masa awal implementasi sistem informasi desa tersebut sehingga dapat meminimalisir kesalahankesalahan ketika menggunakan sistem informasi desa tersebut [10]. 


\section{KESIMPULAN}

Berdasarkan pada hasil desain tampilan aplikasi sistem pelayana masyarakat desa dan pengujian user experience terhadap rancangan user interface yang telah dibuat, maka dapat disimpulkan sebagai berikut:

1. Desain aplikasi untuk sistem pelayanan masyarakat desa berbasis website yang dibutuhkan oleh pemerintah desa Sukamanah telah berhasil dibuat dengan menggunakan metode Goal Directed Design (GDD). User interface yang telah berhasil dibuat merupakan hasil dari pendalaman kebutuhan-kebutuhan untuk sistem informasi desa dengan perangkat desa Sukamanah agar sistem tersebut tepat guna dan dapat mempercepat kinerja dari perangkat desa.

2. Hasil akhir yang akan diperoleh pihak desa Sukamanah berupa rekomendasi tampilan user interface pada sistem informasi desa untuk desa Sukamanah agar dapat membantu mempercepat dan mempermudah kinerja yang dilakukan oleh perangkat desa

\section{DAFTAR PUSTAKA}

[1] Christianisa, E. Delima, R. \& Herlina, T., Game Edukasi Bahasa Inggris Menggunakan Metode Goal Directed Design. Informatika, 10.92-102. 2014.

[2] H.N, I. A., Nugroho, P. I., \& Ferdiana, R., "Pengujian Usability Website Menggunakan System Usability Scale," JURNAL IPTEKKOM: Jurnal Ilmu Pengetahuan \& Teknologi Informasi, 17(1), 31. 2015.

[3] Arifin, Y. Pengenalan Tentang Persona. Diambil kembali dari school Of Computer Science. 2016.
[4] Ichsan, M.F., Sabariah, M.K., \& Effendy, V., "Modeling the User Experience of Interactive Media Application in Introduction to Drawing for Early Childhood Education Using Hierarchical Task Analysis Method, ". 2015.

Available http://journal.uad.ac.id/index.php/Edu

[5] Mauladi, \& Suratno, T., "Analisis Penentu Antarmuka Terbaik Berdasarkan Eye Tracking pada Sistem Informasi Akademik Universitas Jambi," Jurnal

Penelitian Universitas Jambi Seri Sains, 18, 64-68. 2016.

[6] Rasmila., "Evaluasi Website Dengan Menggunakan System Usability Scale (SUS) Pada Perguruan Tinggi Swasta Di Palembang," JUSIFO: Jurnal Sistem Informasi, 02(Vol 2 No 1 (2018): JUSIFO), 108-121. 2018.

[7] Maulana, Y., "Evaluasi Dan Perbaikan Rancangan Antarmuka Pengguna Situs Web Jawa Timur Park Group Menggunakan Metode Goal-Directed Design (GDD)," Jurnal Pengembangan Teknologi Informasi Dan Ilmu Komputer (J-PTIIK) Universitas Brawijaya, 3(7), 7159-7165. 2019.

[8] Tejamukti, A. A., Az-zahra, H. M. and Rokhmawati, R. I., "Pengembangan Antarmuka Website PPPA Daarul Qur' an Malang Dengan Menggunakan Metode Goal Directed Design," Pengembangan Teknologi Informasi dan Ilmu Komputer, 2(12), pp. 6277-6285. 2018.

[9] David, L., Pengertian, Implementasi, dan Pemanfaatan User Experience dalam Bidang TIK. 2016. Available : https://mhs.blog.ui.ac.id/. [accessed: 20 April 2021]

[10] Kurniawan, A., "Chabibi, M. and Dewi, R., 'Pengembangan Sistem Informasi Pelayanan Desa Berbasis Web Dengan Metode Prototyping Pada Desa Leran," JURIKOM (Jurnal Riset Komputer), 7(1). 2020 . 